\title{
COPD in Chinese nonsmokers
}

\author{
Y. Zhou, C. Wang, W. Yao, P. Chen, J. Kang, S. Huang, B. Chen, C. Wang, D. Ni, \\ X. Wang, D. Wang, S. Liu, J. Lu, J. Zheng, N. Zhong and P. Ran
}

ABSTRACT: Little is known about chronic obstructive pulmonary disease (COPD) in Chinese nonsmokers. The present study aimed to investigate the profiles of COPD among nonsmokers based on the Chinese Epidemiological Survey of COPD (CESCOPD).

In the CESCOPD, 20,245 subjects aged 40 yrs or older were interviewed with questionnaires and spirometry tests. Subjects with a post-bronchodilator forced expiratory volume in one second (FEV1)/forced vital capacity (FVC) ratio of $<0.70$ were identified as having COPD. Data of 12,471 nonsmokers and 1,024 smoking COPD patients were analysed in the current study.

The overall prevalence of COPD among nonsmokers was 5.2\% (95\% confidence interval 4.8 5.6). Being male, of advanced age, lower body mass index (BMI) and lower educational level, having exposure to environmental tobacco smoke, coal and/or biomass smoke, poor ventilation in the kitchen, a family history of respiratory disease and recurrent childhood cough were all independently associated with a higher risk of having COPD among nonsmokers. Nonsmokers with respiratory symptoms without airflow limitation showed a somewhat different pattern of risk factors. Nonsmokers with COPD were less likely to present with chronic productive coughs and lower BMI, while more likely to have received a physician diagnosis of asthma and respiratory diseases in childhood, than smokers with COPD.

Chronic obstructive pulmonary disease is prevalent among Chinese nonsmokers, and nonsmoking chronic obstructive pulmonary disease may have different profiles from smoking chronic obstructive pulmonary disease.

KEYWORDS: Biomass smoke, chronic obstructive pulmonary disease, environmental tobacco smoke, epidemiology, nonsmokers

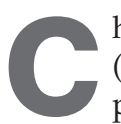

hronic obstructive pulmonary disease (COPD) has become a major public health problem worldwide, with a growing population prevalence of $4-10 \%$ based on spirometry tests [1]. Among the major causes of COPD, the role of tobacco smoking is well recognised [2] and, accordingly, earlier studies of COPD have been largely focused on the smoking rather than the nonsmoking population. However, recently, large-scale and/or nationwide studies have showed that a significant percentage of COPD patients have never smoked $[3,4]$, which is becoming a finding of which researchers are becoming increasingly aware [5, 6]. Differences in exposure to smoking, lifestyles and behaviours may be the underlying causes of the varying prevalence, characteristics and potential risk factors regarding nonsmoker COPD across countries and areas. For instance, indoor air pollution and respiratory problems in childhood have been linked to COPD among nonsmokers $[5,6]$ and may be more common in developing compared with developed countries. Insights into the epidemiology of COPD in nonsmokers may thus be of interest.

In the recently updated Global Initiative for Chronic Obstructive Lung Disease (GOLD) guidelines [7], stage 0 (chronic symptoms without airflow limitation) was removed from the classification of COPD severity; however, DE MARCO et al. [8] argued that the GOLD stage 0, as with other GOLD stages, is characterised by the presence of similar risk factors and by a similar high demand for medical assistance in young adults. To clarify the controversy, the goal of the present paper is not just to illustrate the prevalence and risk factors of COPD among nonsmokers, but to focus specifically on differences in risk factors between various GOLD stages in nonsmokers and the differences in profiles of COPD between smokers and nonsmokers, based on the findings as yet not well delineated in the report from the Chinese
AFFILIATIONS

For affiliations please see the Acknowledgements section.

CORRESPONDENCE

P. Ran

The State Key Laboratory of

Respiratory Disease, Guangzhou Institute of Respiratory Diseases, The First Affiliated Hospital Guangzhou Medical University 195 Dongfeng Xi Road Guangzhou Guangdong 510182 China Fax: 862081340482 E-mail: pxran@gzhmc.edu.cn

Received:

June 042008

Accepted after revision:

November 032008

\section{SUPPORT STATEMENT}

This study was funded by the Chinese Central Government Key Research Projects of the 10th National Fiveyear Development Plan (grant 2001BA703B03(A) to P. Ran) and in part by a Guangdong Key Research Project (China), grant B30301 to P. Ran.

STATEMENT OF INTEREST None declared. 
Epidemiological Survey of COPD (CESCOPD) study [9]. The CESCOPD was the first large-scale cross-sectional survey on COPD in China using GOLD diagnostic criteria, conducted between September 2002 and September 2004.

\section{MATERIALS AND METHODS \\ Study design and subjects}

Briefly, the CESCOPD was conducted in seven provinces/ cities (Beijing, Tianjin, Liaoning, Shanghai, Guangdong, Shaanxi and Chongqing), covering a population of $>230$ million and a wide range of geographic areas in China. In the CESCOPD study, 25,267 subjects aged $\geqslant 40$ yrs were recruited using a multistage cluster sampling strategy with urban communities or rural villages as cluster units. Data of 20,245 subjects (9,434 in rural and 10,811 in urban areas) who completed acceptable spirometry and questionnaires were available for analyses. The overall response rate was 79.0\% $(20,245$ out of 25,267$)$. The main results of CESCOPD were reported elsewhere [9]. Since one of the aims of the current study was to compare and contrast the different profiles of COPD in nonsmokers with those in smokers, the data of 12,471 nonsmokers aged $\geqslant 40$ yrs were analysed in addition to the data of 1,024 COPD patients who were smokers. Ethical approval of the present study protocol was obtained from each participating Institutional Review Board for Human Studies and informed consent was obtained from all participants. The present study was consistent with the Helsinki declaration.

\section{Questionnaire}

The questionnaire applied in the current study was revised from those used in the global Burden of Obstructive Lung Disease (BOLD) study [10] and in previous COPD studies in China. Its validation was approved by the BOLD study centre through a pilot study in Guangzhou City (China). "Nonsmokers" referred to subjects who had never smoked in their lifetime. "Passive smokers" were subjects exposed to environmental tobacco smoke at home or in the workplace. Exposure to biomass smoke was defined as using biological material (mainly wood, charcoal, grass and crop residues or dung) for cooking or heating for $\geqslant 1 \mathrm{yr}$. Using coal for cooking or heating for $\geqslant 1 \mathrm{yr}$ was identified to have exposure to coal. Poor ventilation referred to subjects who did not have a ventilator in the kitchen. Subjects with a parent or sibling diagnosed with chronic bronchitis, emphysema, asthma or COPD were deemed as having a family history of respiratory diseases. A cut-off point of occupational exposure to dusts/ gases/fumes for $1 \mathrm{yr}$ classified the subjects into two groups (yes or no). The frequency of cough in childhood (recurrent, sometimes and seldom) was identified based on self-reported information.

\section{Spirometry and diagnostic criteria}

Portable spirometers (Cardinal Health, Basingstoke, UK) were used in the current study. The spirometry procedure recommended by the American Thoracic Society [11] was conducted on all eligible subjects. Subjects with airflow limitations underwent bronchodilation tests within 15-20 min of being given a dose of $200 \mu \mathrm{g}$ of salbutamol (Ventolin; GlaxoSmithKline, Uxbridge, UK) inhaled through a 500-mL spacer. According to the diagnostic criteria of GOLD [7], subjects with a postbronchodilator forced expiratory volume in one second
(FEV1)/forced vital capacity (FVC) ratio of $<0.70$ were diagnosed as having COPD. Subjects who presented with a productive cough lasting $\geqslant 3$ months $\cdot \mathrm{yr}^{-1}$ for $\geqslant 2 \mathrm{yrs}$ but showed a post-bronchodilator FEV1/FVC ratio of $\geqslant 0.70$ were defined as stage 0 according to the previous GOLD severity classification [12]. COPD stages I-IV were determined according to the current criteria of GOLD severity [7]. Predicted normative values of FEV1 in the Chinese population were derived from the 1993 European Coal and Steel Community (ECSC) equations and were adjusted with conversion factors recommended by ZHENG and ZHONG [13], which are widely used in the present authors' clinical practices.

\section{Quality control}

Detailed quality control information for the CESCOPD has been previously reported elsewhere [9]. In brief, uniform protocol, instruments, strategies and procedures were used among all sites. Each spirometry operator had been well trained, the spirometer was calibrated daily and spirometry results were sent every 2 weeks to Guangzhou for quality control. As reported by ENRIGHT et al. [14], a quality grade (A-F) was determined based on acceptable manoeuvres and repeatability of the FEV1 and FVC. Spirometry results with grades $\mathrm{A}, \mathrm{B}$ or $\mathrm{C}$ (at least two acceptable manoeuvres, with FEV1 matching within $0.2 \mathrm{~L}$ ) were considered acceptable for analysis.

\section{Statistical analysis}

The correlations between COPD prevalence and the proportion of exposure to biomass smoke were analysed in each area. Calculations of odds ratios (ORs), relative risk ratios (RRRs) and $95 \%$ confidence intervals (CIs) for COPD with respect to potential risk factors were completed with binary logistic regression and multinomial logistic regression. Subjects with neither GOLD stage 0 nor GOLD stage I subjects or higher were the reference category (or reference population) in the multinomial logistic regression analysis. RRRs were the ORs relative to the reference population and, thus, RRRs were converted into ORs in the current article. Variables were treated as dummy, ordinal categorical or continuous variables when appropriate. Variables including area, sex, age group, body mass index (BMI), passive smoking, occupational exposure to dusts/gases/fumes, exposure to biomass and coal for cooking and heating, ventilation of the kitchen, family history of respiratory disease, frequency of cough in childhood and level of education were all included into the final logistic regression model. The consistency of any finding was investigated by analyses of the dose-response pattern where appropriate (i.e. length and intensity of coal or biomass exposure). No interactions were forced into the final logistic regression model. A p-value of $<0.05$ was considered statistically significant.

\section{RESULTS}

In the CESCOPD, nonsmokers accounted for $61.6 \%$ of the total population, $25.7 \%$ of males and $88.7 \%$ of females. Among nonsmokers, the overall prevalence of COPD was $5.2 \%$, including $1.4 \%$ (95\% CI 1.2-1.7) in GOLD stage I and 3.7\% (95\% CI 3.4-4.1) in GOLD stages II-IV. A further 4.8\% (95\% CI 4.4-5.1) of nonsmokers were airway unobstructed and presented with a productive cough lasting $\geqslant 3$ months $\cdot \mathrm{yr}^{-1}$ for 
TABLE 1 Prevalence of Global Initiative for Chronic Obstructive Lung Disease (GOLD) chronic obstructive pulmonary disease (COPD) stages among nonsmokers

\begin{tabular}{lccccc} 
& Subjects $\mathbf{n}$ & Stage $\mathbf{0}^{\boldsymbol{\#}}$ & Stage I & Stage II or higher & Stage I or higher \\
\hline Male & 2235 & $4.7(3.9-5.7)$ & $2.3(1.7-3.0)$ & $6.5(5.6-7.6)$ & $8.8(7.7-10.1)$ \\
Female & 10236 & $4.8(4.4-5.2)$ & $1.2(1.0-1.5)$ & $3.1(2.8-3.5)$ & $4.4(4.0-4.8)$ \\
Total & 12471 & $4.8(4.4-5.1)$ & $1.4(1.2-1.7)$ & $3.7(3.4-4.1)$ & $5.2(4.8-5.6)$ \\
\hline
\end{tabular}

Data are presented as \% (95\% confidence interval), unless otherwise stated. *: one of previous GOLD COPD stages, defined as presenting with chronic cough with sputum for $\geqslant 2$ yrs for $\geqslant 3$ months $\cdot y r^{-1}$ without obstruction.

$\geqslant 2$ yrs, which would have been regarded as stage 0 with the previous GOLD severity classification (table 1).

Among 1,668 subjects with COPD diagnosed using spirometry in the CESCOPD, 644 (38.6\%) had never smoked. Unlike those with smoking-related COPD, nonsmoking COPD patients were less likely to have a chronic cough and expectoration, lower BMI, lower FEV1/FVC ratio and FEV1 \% predicted values and previous medical records of chronic bronchitis or COPD, while more likely to have received a physician diagnosis of asthma and to have suffered from respiratory diseases in childhood. Females accounted for the majority of nonsmoking COPD subjects. There was no significant difference between smoking and nonsmoking COPD patients in age, family history of respiratory diseases, activity limitation, physician diagnosis of emphysema, proportion and scores of dyspnoea, geographic distribution (urban/rural), percentage and duration of occupational exposure to dusts/gases/fumes and percentage of wheezing (table 2).

Regarding the prevalence of COPD in nonsmokers, both GOLD stage I and stage II-IV COPD was higher in males,

\section{TABLE 2 Characteristics of chronic obstructive pulmonary disease (COPD) among nonsmokers compared with those in} smokers

\begin{tabular}{|c|c|c|c|}
\hline Characteristics & Smoking COPD & Nonsmoking COPD & $p$-value \\
\hline Subjects $n$ & 1024 & 644 & \\
\hline Urban & $515(50.3)$ & $323(50.2)$ & 0.956 \\
\hline Age yrs & $66.0 \pm 10.3$ & $65.7 \pm 11.3$ & 0.627 \\
\hline FEV $1 / F V C \%$ & $59.8 \pm 10.8$ & $60.8 \pm 9.5$ & 0.049 \\
\hline FEV $1 \%$ pred & $63.7 \pm 21.7$ & $67.8 \pm 23.5$ & $<0.001$ \\
\hline Exposure to dusts/gases/fumes & $253(24.7)$ & $141(21.9)$ & 0. 188 \\
\hline Duration of exposure to dusts/gases/fumes yrs & $7.3 \pm 14.9$ & $6.3 \pm 13.7$ & 0.153 \\
\hline Family history of respiratory diseases & $349(34.1)$ & $191(29.7)$ & 0.060 \\
\hline Chronic cough in childhood & & & 0.007 \\
\hline Recurrent & $36(3.5)$ & $43(6.7)$ & \\
\hline \multicolumn{4}{|l|}{ Respiratory symptoms } \\
\hline Chronic cough & $498(48.6)$ & $236(36.6)$ & $<0.001$ \\
\hline Chronic phlegm & $467(45.6)$ & $192(29.8)$ & $<0.001$ \\
\hline Wheezing & $300(29.3)$ & $188(29.2)$ & 0.964 \\
\hline Dyspnoea & $425(45.9)$ & $258(43.9)$ & 0.431 \\
\hline \multicolumn{4}{|l|}{ Physician diagnosis } \\
\hline Emphysema & $140(13.7)$ & $73(11.3)$ & 0.164 \\
\hline Chronic bronchitis & 327 (31.9) & $158(24.5)$ & 0.001 \\
\hline COPD & $58(5.7)$ & $22(3.4)$ & 0.036 \\
\hline Asthma & $101(9.9)$ & $91(14.1)$ & 0.008 \\
\hline
\end{tabular}

Data are presented as $n(\%)$ or mean \pm SD, unless otherwise stated. FEV1: forced expiratory volume in one second; FVC: forced expiratory volume; BMI: body mass index $\%$ pred: \% predicted. 
TABLE 3 Prevalence of Global Initiative for Chronic Obstructive Lung Disease (GOLD) chronic obstructive pulmonary disease (COPD) stages among nonsmokers

\begin{tabular}{|c|c|c|c|c|}
\hline & Subjects $n$ & Stage 0 & Stage I & Stage II-IV \\
\hline \multicolumn{5}{|l|}{ Sex } \\
\hline Female & 10236 & $4.8(4.4-5.2)$ & $1.2(1.0-1.5)$ & $3.1(2.8-3.5)$ \\
\hline \multicolumn{5}{|l|}{ Age yrs } \\
\hline $40-49$ & 4337 & $3.9(3.3-4.5)$ & $0.4(0.3-0.7)$ & $1.1(0.9-1.5)$ \\
\hline$\geqslant 70$ & 2072 & $5.8(4.9-6.9)$ & $3.7(3.0-4.6)$ & $10.0(8.8-11.4)$ \\
\hline \multicolumn{5}{|l|}{ Education yrs } \\
\hline 0 & 5592 & $4.8(4.3-5.4)$ & $2.0(1.7-2.4)$ & $5.7(5.1-6.3)$ \\
\hline $1-9$ & 5945 & $4.5(4.0-5.1)$ & $0.9(0.7-1.2)$ & $2.2(1.9-2.6)$ \\
\hline$\geqslant 10$ & 934 & $6.1(4.7-7.8)$ & $1.2(0.7-2.1)$ & $2.0(1.3-3.2)$ \\
\hline \multicolumn{5}{|l|}{$\mathrm{BMI} \mathbf{k g} \cdot \mathrm{m}^{-2}$} \\
\hline$\geqslant 28.0$ & 1626 & $5.7(4.7-7.0)$ & $1.3(0.8-2.0)$ & $3.4(2.6-4.4)$ \\
\hline \multicolumn{5}{|c|}{ Passive smoking ${ }^{\#}$} \\
\hline No & 2716 & $4.3(3.6-5.2)$ & $1.1(0.8-1.6)$ & $3.3(2.7-4.1)$ \\
\hline Yes & 9755 & $4.9(4.5-5.3)$ & $1.5(1.3-1.8)$ & $3.9(3.5-4.3)$ \\
\hline \multicolumn{5}{|c|}{ Respiratory disease in family } \\
\hline None & 9761 & $4.0(3.7-4.5)$ & $1.3(1.1-1.5)$ & $3.4(3.0-3.7)$ \\
\hline 1 affected & 2176 & $6.4(5.4-7.5)$ & $2.0(1.5-2.7)$ & $4.7(3.9-5.7)$ \\
\hline$\geqslant 2$ affected & 534 & $11.0(8.7-14.0)$ & $1.9(1.0-3.4)$ & $6.6(4.7-9.0)$ \\
\hline \multicolumn{5}{|c|}{ Chronic cough in childhood } \\
\hline Recurrent & 335 & $14.0(10.7-18.2)$ & $3.6(2.0-6.2)$ & $9.3(6.6-12.9)$ \\
\hline Sometimes & 580 & $8.4(6.4-11.0)$ & $1.7(0.9-3.2)$ & $5.9(4.2-8.1)$ \\
\hline Seldom & 11556 & $4.3(3.9-4.7)$ & $1.3(1.2-1.6)$ & $3.5(3.2-3.8)$ \\
\hline \multicolumn{5}{|c|}{ Exposure to biomass for heating } \\
\hline Yes & 9128 & $4.9(4.4-5.3)$ & $1.4(1.2-1.7)$ & $3.6(3.2-4.0)$ \\
\hline No & 3343 & $4.5(3.8-5.2)$ & $1.5(1.1-1.9)$ & $4.1(3.5-4.9)$ \\
\hline \multicolumn{5}{|c|}{ Exposure to coal for heating } \\
\hline Yes & 1923 & $6.6(5.6-7.8)$ & $1.0(0.7-1.6)$ & $5.6(4.7-6.7)$ \\
\hline No & 10248 & $4.4(4.0-4.8)$ & $1.5(1.3-1.7)$ & $3.4(3.1-3.8)$ \\
\hline \multicolumn{5}{|c|}{ Poor ventilation in kitchen } \\
\hline Yes & 4991 & $5.2(4.6-5.9)$ & $1.6(1.3-2.0)$ & $4.6(4.0-5.2)$ \\
\hline No & 7480 & $4.4(4.0-4.9)$ & $1.3(1.1-1.6)$ & $3.2(2.8-3.6)$ \\
\hline \multicolumn{5}{|c|}{ Occupational exposure to dusts/gases/fumes } \\
\hline Yes & 2508 & $5.1(4.3-6.1)$ & $2.0(1.5-2.7)$ & $3.6(2.9-4.4)$ \\
\hline No & 9963 & $4.7(4.3-5.1)$ & $1.3(1.1-1.5)$ & $3.8(3.4-4.2)$ \\
\hline
\end{tabular}

Data are presented as $\%$ (95\% confidence interval), unless otherwise stated. BMl: body mass index. ${ }^{*}$ : defined as exposure to environmental tobacco smoke.

older adults, subjects with lower BMI or less education, individuals who had a family history of respiratory diseases or a history of recurrent cough in childhood, subjects whose kitchens had poor ventilation and those exposed to biomass smoke for cooking or heating and environmental tobacco smoke. The population who used coal for heating had a higher crude prevalence of COPD in both GOLD stage 0 and stage II-IV (table 3). The prevalence of COPD in each area was correlated to the proportion of exposure to biomass smoke after adjustment for sex and age $(r=0.771, p=0.002$; fig. 1$)$. 


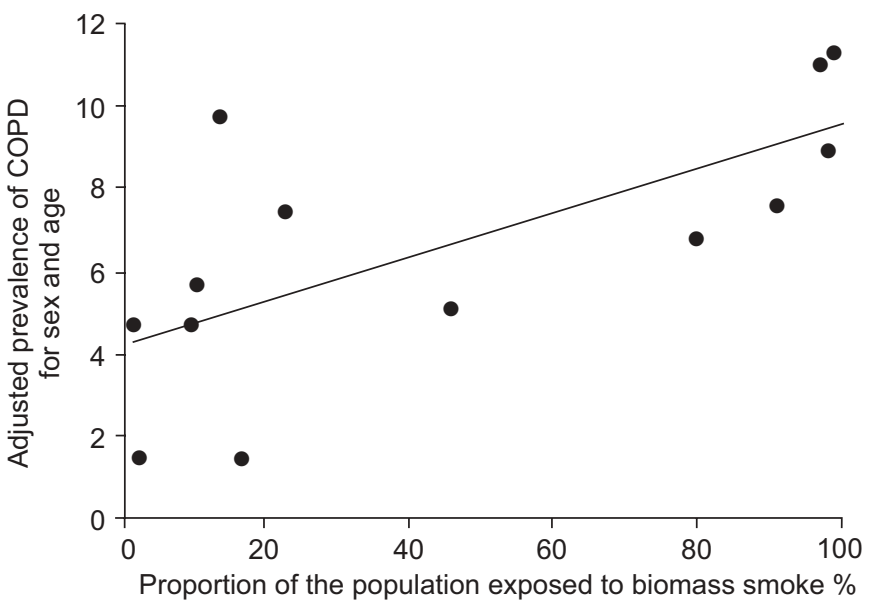

FIGURE 1. Relationship between the adjusted prevalence of chronic obstructive pulmonary disease (COPD) for sex and age and the proportion who were exposed to biomass smoke. : a site. $r=0.771, p=0.002$.

Multinomial logistic regression showed that advanced age, a family history of respiratory disease and a chronic cough in childhood were risk factors that were common to GOLD stages 0 , I and II or higher, with statistically significant ORs. Subjects with stage I and stage II or higher COPD had similar risk factors ( $p$-values for comparison of the adjusted ORs for risk factors between stage I and stage II or higher were $>0.05$; data not shown): being male, advanced age, a family history of respiratory diseases, a history of recurrent cough in childhood, and exposure to environmental tobacco smoke were all associated with an increased likelihood of developing stage I or stages II-IV COPD, using subjects with neither stage 0 nor stage I-IV as a reference population (table 4).

Comparatively, subjects with stage 0 COPD showed some differences in risk factors. While advanced age was associated with all stages, it was more strongly associated with stages I-IV than with stage 0 . In addition, occupational exposure to dusts/gases/fumes was exclusively associated with stage 0 , whereas biomass smoke exposure for cooking, less education and lower BMI were only associated with stage II-IV (table 4). Poor ventilation in the kitchen and exposure to coal for heating were significantly correlated to both stage II-IV and stage 0 COPD after adjustment (table 4). The consistency of the present finding was observed by analyses for dose-response pattern when the appropriate variable (i.e. length of coal or biomass exposure) was treated as a continuous variable instead of a relative categorical variable for entering into the final logistic regression model (see online supplementary material table $1 S)$.

Analyses repeated in nonsmoking males showed that biomass smoke exposure was associated with stages II or higher COPD, with an OR of 1.76 (95\% CI 1.15-2.70), using subjects with neither stage 0 nor stage I-IV as a reference population. A dose-response pattern between stages II or higher COPD and years of exposure to biomass smoke were observed after adjustment ( $p=0.006$; data not shown).

Consistent with the results from multinomial logistic regression analyses, multivariable binary logistic regression analyses showed that being male, advanced age, lower BMI, a family history of respiratory disease, a history of recurrent cough in childhood, less education, exposures to biomass for cooking, exposure to coal for heating, poor ventilation in the kitchen and environmental tobacco smoke were associated with a risk for stage I-IV COPD in nonsmokers (table 5). Length of exposure to biomass for cooking and coal for heating were found to have a dose-response pattern with COPD, with ORs of 1.08 (95\% CI 1.03-1.13) and 1.11 (95\% CI 1.02-1.22), respectively, when they were treated as continuous variables instead of relative categorical variables for entering into the final logistic regression model. The dose-response association between COPD and length of exposure to biomass smoke was also observed in nonsmoking males (OR 1.13, 95\% CI 1.03-1.24; $\mathrm{p}=0.012$; data not shown in the table).

\section{DISCUSSION}

The present article has reported in detail the prevalence and potential risk factors for COPD using GOLD stages among nonsmokers, and distinct profiles of COPD in nonsmokers versus smokers, based on the dataset of CESCOPD.

First, the prevalence of COPD according to GOLD diagnostic criteria among Chinese nonsmokers aged $\geqslant 40$ yrs was $5.2 \%$. As with results from other spirometry-based surveys, COPD prevalence in nonsmokers showed variation across countries and areas: the current findings were similar to those in Mexico City (6.2\%) and Caracas (6.6\%), but lower than those in three other Latin American cities (Sao Paulo 12.5\%, Montevideo $15.3 \%$ and Santiago $15.9 \%$ ) using the same diagnostic criteria in the same age groups [3]. COPD prevalence in nonsmokers was $8.8 \%$ in Koreans aged $\geqslant 45$ yrs and $9.1 \%$ in subjects from the USA aged $\geqslant 30$ yrs $[15,16]$, according to the same diagnostic criteria. In the present study, it was found that male nonsmokers were more likely than female nonsmokers to have COPD (8.8 versus $4.4 \%$, respectively), consistent with findings from Germany and Norway [16] but in contrast to the findings from Australia, Iceland and Poland, which showed a greater prevalence of GOLD stage II or higher COPD among female nonsmokers than in male nonsmokers [17]. A higher prevalence of COPD in female $(2.1 \%)$ versus male $(0.8 \%)$ nonsmokers (2.1 versus $0.8 \%$, respectively) was also noted in the Canadian National Population Health Survey, which used the physician diagnosis of COPD [18]. In addition, nonsmokers accounted for $38.6 \%$ of COPD patients in the current study compared with smaller percentages in the USA (24.9\%) [19], the UK (22.9\%) [20] and Spain (23.4\%) [21], suggesting that other risk factors, independent of smoking, may be contributing to COPD in China more immensely than in developed countries.

Secondly, the present study found different profiles between smoking and nonsmoking COPD patients. BEHRENDT [22] reported that few $(12.1 \%)$ nonsmokers with COPD had ever received a physician diagnosis of chronic bronchitis or emphysema, but he did not compare them with COPD smokers. The current findings clearly displayed different profiles and risk factors of COPD among never-smokers versus smokers, suggesting that the two subgroups of COPD may arise from different aetiologies. 
TABLE 4 Adjusted odds ratio (OR) of potential risk factors for previous Global Initiative for Chronic Obstructive Lung Disease (GOLD) staging among nonsmoking chronic obstructive pulmonary disease (COPD) subjects

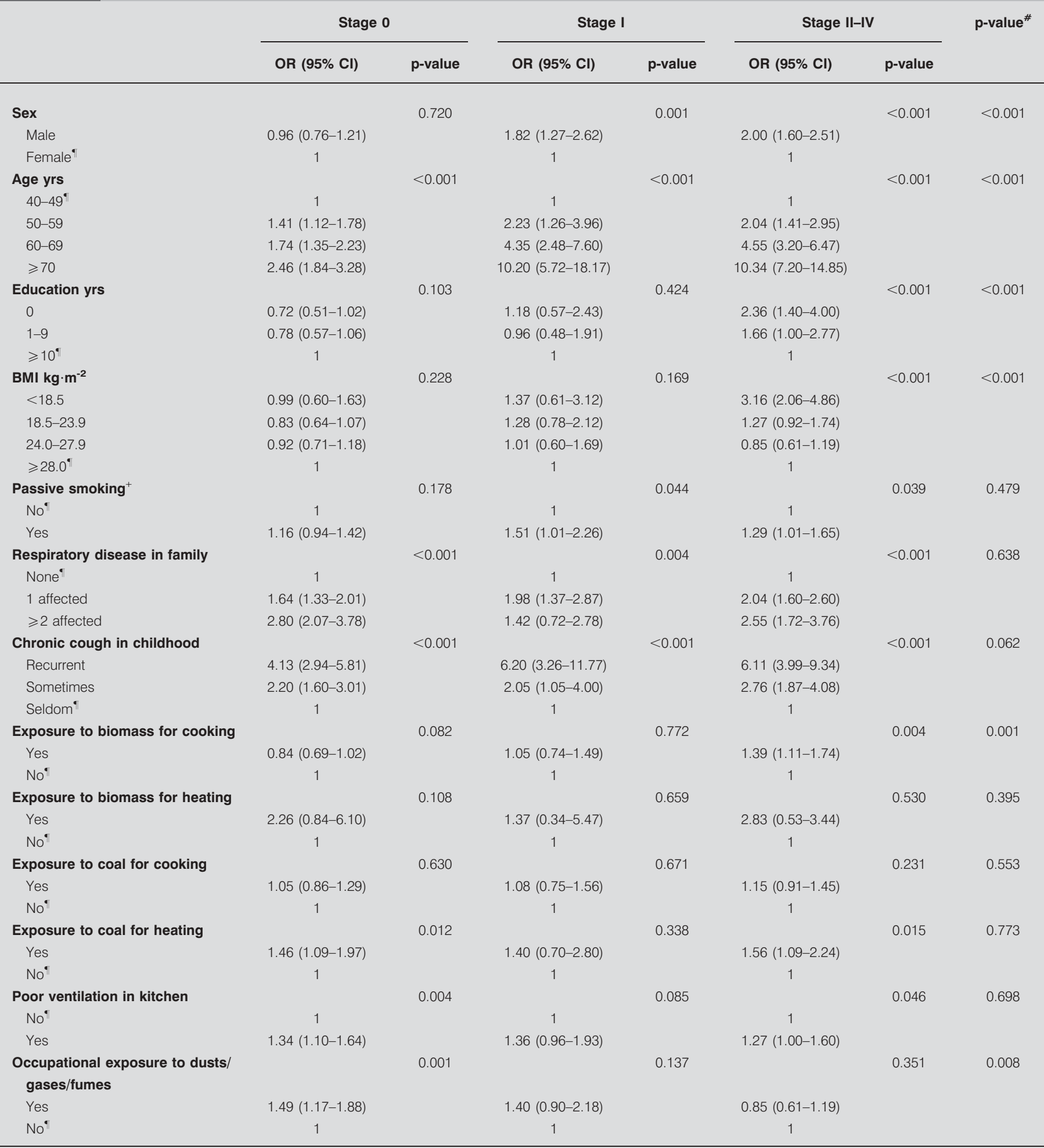

$\mathrm{Cl}$ : confidence interval; BMI: body mass index. ${ }^{\#}$ : comparison between OR for stage 0 and stage II-IV; ${ }^{\circ}$ : reference values; ${ }^{+}$: defined as exposure to environmental tobacco smoke. 


\begin{tabular}{|c|c|c|c|}
\hline \multirow[t]{2}{*}{ TABLE 5} & \multicolumn{3}{|c|}{$\begin{array}{l}\text { Adjusted odds ratio (OR) of risk factors for } \\
\text { nonsmoking chronic obstructive pulmonary } \\
\text { disease subjects }\end{array}$} \\
\hline & & Adjusted OR $(95 \% \mathrm{Cl})$ & p-value \\
\hline \multicolumn{3}{|l|}{ Sex } & $<0.001$ \\
\hline Male & & $1.97(1.62-2.40)$ & \\
\hline Female $^{\#}$ & & 1 & \\
\hline \multicolumn{3}{|l|}{ Age yrs } & $<0.001$ \\
\hline $40-49^{\#}$ & & 1 & \\
\hline $50-59$ & & $2.01(1.47-2.74)$ & \\
\hline $60-69$ & & $4.15(3.08-5.59)$ & \\
\hline$\geqslant 70$ & & $8.93(6.57-12.15)$ & \\
\hline \multicolumn{3}{|c|}{ Education yrs } & 0.001 \\
\hline 0 & & $1.44(0.95-2.17)$ & \\
\hline $1-9$ & & $1.97(1.28-3.02)$ & \\
\hline$\geqslant 10^{\#}$ & & 1 & \\
\hline \multicolumn{3}{|l|}{ BMI $\mathbf{k g} \cdot \mathrm{m}^{-2}$} & $<0.001$ \\
\hline$<18.5$ & & $2.69(1.83-3.94)$ & \\
\hline $18.5-23.9$ & & $1.27(0.97-1.66)$ & \\
\hline $24.0-27.9$ & & $0.88(0.67-1.17)$ & \\
\hline$\geqslant 28.0^{\#}$ & & 1 & \\
\hline \multicolumn{3}{|c|}{ Passive smoking } & 0.014 \\
\hline $\mathrm{No}^{\#}$ & & 1 & \\
\hline Yes & & $1.31(1.06-1.61)$ & \\
\hline \multicolumn{3}{|c|}{ Respiratory disease in family } & $<0.001$ \\
\hline None ${ }^{\#}$ & & 1 & \\
\hline 1 affected & & $2.07(1.68-2.54)$ & \\
\hline$\geqslant 2$ affecte & & $2.11(1.50-2.97)$ & \\
\hline \multicolumn{3}{|c|}{ Exposure to biomass for cooking } & 0.006 \\
\hline Yes & & $1.31(1.08-1.58)$ & \\
\hline $\mathrm{No}^{\#}$ & & 1 & \\
\hline \multicolumn{3}{|c|}{ Exposure to coal for heating } & 0.017 \\
\hline Yes & & $1.48(1.07-2.05)$ & \\
\hline $\mathrm{No}^{\#}$ & & 1 & \\
\hline \multicolumn{3}{|c|}{ Poor ventilation in kitchen } & 0.018 \\
\hline $\mathrm{No}^{\#}$ & & 1 & \\
\hline Yes & & $1.27(1.04-1.55)$ & \\
\hline \multicolumn{3}{|c|}{ Chronic cough in childhood } & $<0.001$ \\
\hline Recurrent & & $5.20(3.59-7.52)$ & \\
\hline Sometimes & & $2.38(1.68-3.36)$ & \\
\hline Seldom ${ }^{\#}$ & & 1 & \\
\hline \multicolumn{3}{|c|}{$\begin{array}{l}\text { Occupational exposure to } \\
\text { dusts/gases/fumes }\end{array}$} & 0.826 \\
\hline Yes & & $1.03(0.79-1.35)$ & \\
\hline $\mathrm{No}^{\#}$ & & 1 & \\
\hline
\end{tabular}

Two variables (exposure to biomass for heating and exposure to coal for cooking) were not shown in the table due to $p$-values being $\geqslant 0.05$. Cl: confidence interval; BMI: body mass index. ${ }^{*}$ : reference values; " : defined as exposure to environmental tobacco smoke; ${ }^{+}$: the OR was 1.24 (95\% Cl $1.01-$ 1.52) after adjustment for all variables in the table except for education, which was considered to be related to occupation $(r=-0.182, p<0.001)$.

Thirdly, the current results showed that stage I, but not stage 0 , shared similar risk factors with stage II or higher COPD. Risk factors such as being male, advanced age, a family history of respiratory disease, a recurrent cough in childhood and an exposure to environmental tobacco smoke were found to contribute to both stage I and stage II or higher COPD among nonsmokers in the present study and have been described in several previous studies [3, 23-25]. While it has been implied that the British Thoracic Society criteria have an advantage over the GOLD criteria, which can lead to over-diagnosis of COPD in older adults [7], the current study showed equivalently strong correlations between age and stage I or stage II or higher. However, stage 0 was found not to be associated with age, sex, education, occupation and BMI to the same degree as stage II or higher and stage I. These findings were also observed among smokers in the present study (data not shown), and were consistent with the study by VESTBO and LANGE [26], in which GOLD stage 0 was concluded to be of little help in identifying subjects at risk for COPD.

In addition to well-documented causative factors (such as tobacco smoking) for COPD, other factors may also have a role in the aetiology of the disease. Of these, genetic susceptibility has attracted general attention [27]. Nonetheless, $\alpha_{1}$-antitrypsin deficiency is still the only genetic factor definitively identified to date and this only accounts for $<1 \%$ of COPD cases and has not been found in the Chinese. Thus, the current authors had a good reason to assume that the association between COPD and family history of respiratory diseases in the present study mainly arose from environmental effects (such as environmental tobacco, coal and biomass smoke). Unlike in developed countries, indoor air pollution, including environmental tobacco smoke, coal and biomass combustion, may contribute substantially to COPD in China and other developing countries [25, 28-30], especially for those without smoking habits. In the present study, $78.2 \%(9,755$ out of 12,471$)$ of nonsmokers had exposure to environmental tobacco smoke that was linked to COPD. This correlated well with the literature indicated that exposure to parental smoking in childhood potentially has an effect on the adult onset of obstructive lung diseases and chronic respiratory symptoms and that environmental tobacco smoke is associated with higher bronchial responsiveness and declined pulmonary function $[25,29]$. Another indoor pollution shown to be related to COPD in developing countries arises from coal and biomass combustion [28, 30-33]. In the present study, 44.6\% (5,565 out of 12,471$)$ and $73.2 \%(9,128$ out of 12,471$)$ of nonsmokers had exposure to biomass smoke and coal, respectively, $40 \%(4,991$ out of 12,741) had poor ventilation in the kitchen and the levels of exposure were also related to the prevalence of COPD. These findings are interesting, because many Chinese nonsmokers, especially those in the rural areas, were exposed to biomass smoke and coal for cooking or heating. Hence, the contribution of coal and biomass smoke to COPD should not be overlooked. In addition, in the present study, COPD was associated with exposure to biomass for cooking and coal for heating, but not with exposure to biomass for heating or with coal for cooking, which can be partially explained by the different types of fuels and the status of burning. Generally, there was less biomass smoke generated from heating than from cooking because relatively clean types of fuels (i.e. charcoal) were kept for heating, while wood, crop residues, corncobs and grass were used for cooking. When used for heating purposes, coal does not burn fully and indoor ventilation was commonly poor. Therefore, coal produces 
more harmful pollutants when used for heating as opposed to for cooking. Interestingly, as emphasised by previous studies, exposure to biomass pollutants was not only an occupational risk factor, being related to the direct use of biomass for cooking, increasing risk of COPD in females, but also was probably related to increasing risk of COPD in men exposed during childhood and even without direct use of the kitchen [33]. The current study found that biomass for cooking was associated with COPD in nonsmoking males, which could be partially explained by the persistent higher levels of pollutants in living and sleeping areas of the home.

While some studies have noted occupational exposure to dusts/gases/fumes as one of the risk factors for COPD [9, 34], the present authors did not see any significant correlation between COPD and exposure to occupational dusts/gases/ fumes among nonsmokers when education was taken into account in the logistic regression model. This was probably due to the reduction of samples after stratification by smoking, due to the healthy worker effect (that is, more healthy individuals were employed in jobs with dusts and fumes) and due to the difference between smokers and nonsmokers in types of exposure to occupational dusts/gases/fumes. When education was excluded from the final logistic regression model, the adjusted OR of occupational exposure for COPD was 1.24 (95\% CI 1.01-1.52; data not shown). However, subjects exposed to occupational dusts/gases/fumes did have more respiratory symptoms than others.

In consistency with PRESCOTT and VestBo [35], lower socioeconomic status as measured by education degree in the current study was associated with COPD among nonsmokers, but such an association might also be a complex function of many risk factors (e.g. occupational exposure, respiratory disease during childhood, undernourished status and poor healthcare). Strong associations between COPD and age among nonsmokers could be attributed not only to the accumulative effects of risk factors over time, but also to the age-related weakening of respiratory muscles that leads to decreased peak expiratory flow and FEV1/FVC by standardised spirometry tests [36]. In the current study, male nonsmokers were more likely to have COPD than female nonsmokers, probably a result of higher exposure to risk factors. While current evidence suggests differential risks for females and males for COPD in different communities (which may be attributed to different exposure to risk factors), the difference in COPD susceptibility between the sexes remains controversial [37, 38]. Nevertheless, the real reasons are expected to be clarified in the near future. In agreement with other studies $[3,24]$, the current results linked lower BMI to COPD, but the causative relationship needs to be further illustrated in future studies. In addition, recurrent chronic cough in childhood appeared to be related to COPD in the present study, as in other studies [6, 23]. However, since some degree of recall bias may exist, more rigorous designs, such as cohort studies, are needed for further validation. Finally, after adjustment for all of the above-mentioned potential risk factors, there was still a difference in risk for COPD among areas (data not shown). As such, there might be risk factors beyond those described, linking COPD to residential areas. Cold, windless, humid and foggy climates, as well as altitudes, have been hypothesised to be associated with COPD in some studies $[3,39]$, but these were not further assessed in the current study.

Some limitations of the present study need to be acknowledged. First, the use of GOLD criteria for COPD may overidentify COPD in older adults [7, 40]. Recently, Ko et al. [40] reported that using the GOLD definition for COPD diagnoses many more COPD cases than using the lower limit of normal values for FEV1/FVC definition in the elderly population (25.9 versus $12.4 \%$, respectively). The current authors presented the prevalence of COPD based on the GOLD stages. However, the current national predicted normative values of FEV1 in China are lacking. As an alternative, the predicted normative values of FEV1 used in the present study were derived from ECSC equations and adjusted with conversion factors recommended by ZHENG and ZHONG [13], which was widely adopted in the current authors' practices. Secondly, recall bias and responder bias may be unavoidable, as with other cross-sectional studies, but a high responder rate in the present study should have minimised the biases. In addition, ecological analysis by area can be subject to ecological fallacy if the association of biomass exposure and COPD were analysed at the individual level.

In conclusion, in the present study, the prevalence, profiles and potential risk factors for chronic obstructive pulmonary disease by the Global Initiative for Chronic Obstructive Lung Disease stages were elucidated among nonsmokers. The results suggested that stage I had similar risk factors for chronic obstructive pulmonary disease to stage II or higher, while stage 0 showed some difference in risk factors to stage II or higher. Being male, advanced age, lower body mass index, less education, a family history of respiratory diseases, a history of recurrent coughs in childhood, coal and biomass exposure, environmental tobacco smoke and poor ventilation in the kitchen were associated with chronic obstructive pulmonary disease among nonsmokers. Compared with the condition in smokers, chronic obstructive pulmonary disease in nonsmokers may arise from a different aetiology.

\section{ACKNOWLEDGEMENTS}

The present authors would like to thank S. Buist (Oregon Health and Science University, Portland, OR, USA), R. Crapo (LDS Hospital, Pulmonary Division, Salt Lake City, UT, USA) and the Burden of Obstructive Lung Diseases committee for providing technical training and the questionnaire; all investigators and local administrators for their great assistance in field surveying in the current study; Z. Guangqiao (Guangzhou Institute of Respiratory Disease, Guangzhou Medical University, Guangzhou, China) and J. Wang (Division of Pulmonary and Critical Care Medicine, Johns Hopkins University, Baltimore, MD, USA) for their assistance in linguistic considerations; and M. Jiang (Guangzhou Institute of Respiratory Disease, Guangzhou Medical University, Guangzhou, China) for her assistance in statistical considerations.

The authors' affiliations are as follows. Y. Zhou, S.Liu, J. Zheng, N. Zhong and P. Ran: The State Key Laboratory of Respiratory Disease, Guangzhou Institute of Respiratory Diseases, the First Affiliated Hospital, Guangzhou Medical University, Guangzhou, China. C. Wang: Beijing Institute of Respiratory Medicine, Beijing Chaoyang Hospital, Capital University of Medical Sciences, Beijing, China. W. Yao: The 
Third Hospital, Peking University, Beijing, China. P. Chen: The Shenyang Military General Hospital, Shenyang, China. J. Kang: The First Affiliated Hospital, China Medical University, Shenyang, China. S. Huang: Ruijin Hospital, Shanghai Jiaotong University, Shanghai, China. B. Chen: The General Hospital, Tianjin Medical University, Tianjin, China. C. Wang: Xinqiao Hospital, the Third Medical University, Chongqing, China. D. Ni: Xijing Hospital, the Fourth Military Medical University, Xi'an, China. X. Wang: The First Municipal People Hospital of Shaoguan, Shaoguan, China. D. Wang: The Second Hospital of Liwan District of Guangzhou, Guangzhou, China. S. Liu: The First Affiliated Hospital of Jinan University, Guangzhou, China. J. Lu: Dept of Epidermiology, Guangzhou Medical University, Guangzhou, China. All authors contributed equally to this article.

\section{REFERENCES}

1 Halbert RJ, Isonaka S, George D, Iqbal A. Interpreting COPD prevalence estimates: what is the true burden of disease? Chest 2003; 123: 1684-1692.

2 Shahab L, Jarvis MJ, Britton J, West R. COPD prevalence, diagnosis and relation to tobacco dependence of chronic obstructive pulmonary disease in a nationally representative population sample. Thorax 2006; 61: 1043-1047.

3 Menezes AM, Perez-Padilla R, Jardim JR, et al. Chronic obstructive pulmonary disease in five Latin American cities (the PLATINO study): a prevalence study. Lancet 2005; 366: 1875-1881.

4 Fukuchi $Y$, Nishimura M, Ichinose M, et al. COPD in Japan: the Nippon COPD epidemiology study. Respirology 2004; 9: 458-465.

5 Ezzati M, Kammen DM. Indoor air pollution from biomass combustion and acute respiratory infections in Kenya: an exposure-response study. Lancet 2001; 358: 619-624.

6 Mannino DM. Looking beyond the cigarette in COPD. Chest 2008; 133: 333-334.

7 Rabe KF, Hurd S, Anzueto A, et al. Global strategy for the diagnosis, management, and prevention of chronic obstructive pulmonary disease: GOLD executive summary. Am J Respir Crit Care Med 2007; 176: 532-555.

8 de Marco R, Accordini S, Cerveri I, et al. An international survey of chronic obstructive pulmonary disease in young adults according to GOLD stages. Thorax 2004; 59: 120-125.

9 Zhong N, Wang C, Yao W, et al. Prevalence of chronic obstructive pulmonary disease in China - a large population-based spirometry based cross-sectional survey. Am J Respir Crit Care Med 2007; 176: 753-760.

10 Buist AS, Vollmer WM, Sullivan SD, et al. The burden of obstructive lung disease initiative (BOLD): rationale and design. COPD 2005; 2: 277-283.

11 American Thoracic Society. Standardization of spirometry 1994 update. Am J Respir Crit Care Med 1995; 152: 1107-1136.

12 Pauwels RA, Buist AS, Calverley PM, Jenkins CR, Hurd SS. Global strategy for the diagnosis, management, and prevention of chronic obstructive pulmonary disease. NHLBI/WHO Global Initiative for Chronic Obstructive Lung Disease (GOLD) workshop summary. Am J Respir Crit Care Med 2001; 163: 1256-1276.
13 Zheng J, Zhong N. Normative values for pulmonary function testing in Chinese adults. Chin Med J (Engl) 2002; 115: 50-54.

14 Enright PL, Studnicka M, Zielinski J. Spirometry to detect and manage chronic obstructive pulmonary disease and asthma in the primary care setting. In: Wouters EF, Gosselink R, Stam H, eds. Lung Function Testing. Eur Respir Mon 2005; 31: 1-14.

15 Kim DS, Kim YS, Jung KS, et al. Prevalence of chronic obstructive pulmonary disease in Korea: a populationbased spirometry survey. Am J Respir Crit Care Med 2005; 172: 842-847.

16 Celli BR, Halbert RJ, Isonaka S, Schau B. Population impact of different definitions of airway obstruction. Eur Respir J 2003; 22: 268-273.

17 Buist AS, McBurnie MA, Vollmer WM, et al. International variation in the prevalence of COPD (the BOLD Study): a population-based prevalence study. Lancet 2007; 370: 741-750.

18 Chen Y, Breithaupt K, Muhajarine N. Occurrence of chronic obstructive pulmonary disease among Canadians and sex-related risk factors. J Clin Epidemiol 2000; 53: 755-761.

19 Whittemore AS, Perlin SA, DiCiccio Y. Chronic obstructive pulmonary disease in lifelong nonsmokers: results from NHANES. Am J Public Health 1995; 85: 702-706.

20 Birring SS, Brightling CE, Bradding P, et al. Clinical, radiologic, and induced sputum features of chronic obstructive pulmonary disease in nonsmokers: a descriptive study. Am J Respir Crit Care Med 2002; 166: 1078-1083.

21 Peña VS, Miravitlles M, Gabriel R, et al. Geographic variations in prevalence and underdiagnosis of COPD: results of the IBERPOC multicentre epidemiological study. Chest 2000; 118: 981-989.

22 Behrendt C. Mild and moderate-to-severe COPD in nonsmokers: distinct demographic profiles. Chest 2005, 128: 1239-1244.

23 Edwards CA, Osman LM, Godden DJ, Douglas JG. Wheezy bronchitis in childhood: a distinct clinical entity with lifelong significance? Chest 2003; 124: 18-24.

24 Harik-Khan RI, Fleg JL, Wise RA. Body mass index and the risk of COPD. Chest 2002; 121: 370-376.

25 David GL, Koh WP, Lee HP, Yu MC, London SJ. Childhood exposure to environmental tobacco smoke and chronic respiratory symptoms in non-smoking adults: the Singapore Chinese Health Study. Thorax 2005; 60: 1052-1058.

26 Vestbo J, Lange P. Can GOLD Stage 0 provide information of prognostic value in chronic obstructive pulmonary disease? Am J Respir Crit Care Med 2002; 166: 329-332.

27 Wood AM, Stockley RA. The genetics of chronic obstructive pulmonary disease. Respir Res 2006; 7: 130-143.

28 Ekici A, Ekici M, Kurtipek E, et al. Obstructive airway diseases in women exposed to biomass smoke. Environ Res 2005; 99: 93-98.

29 Svanes C, Omenaas E, Jarvis D, Chinn S, Gulsvik A, Burney P. Parental smoking in childhood and adult obstructive lung disease: results from the European Community Respiratory Health Survey. Thorax 2004; 59: 295-302.

30 Liu S, Zhou Y, Wang X, et al. Biomass fuels are the probable risk factor for chronic obstructive pulmonary disease in rural South China. Thorax 2007; 62: 889-897. 
31 Díaz E, Bruce N, Pope D, et al. Lung function and symptoms among indigenous Mayan women exposed to high levels of indoor air pollution. Int J Tuberc Lung Dis 2007; 11: 1372-1379.

32 Torres-Duque C, Maldonado D, Pérez-Padilla R, Ezzati M, Viegi G. Biomass fuels and respiratory diseases: a review of the evidence. Proc Am Thorac Soc 2008; 5: 577-590.

33 Orozco-Levi M, Garcia-Aymerich J, Villar J, RamírezSarmiento A, Antó JM, Gea J. Wood smoke exposure and risk of chronic obstructive pulmonary disease. Eur Respir J 2006; 27: 542-546.

34 Balmes J, Becklake M, Blanc P, et al. American Thoracic Society Statement: occupational contribution to the burden of airway disease. Am J Respir Crit Care Med 2003; 167: 787-797.

35 Prescott E, Vestbo J. Socioeconomic status and chronic obstructive pulmonary disease. Thorax 1999; 54: 737-741.
36 Kojima S, Sakakibara H, Motani S, et al. Effects of smoking and age on chronic obstructive pulmonary disease in Japan. J Epidemiol 2005; 15: 113-117.

37 Leynaert B, Bousquet J, Henry C, Liard R, Neukirch F. Is bronchial hyperresponsiveness more frequent in women than in men? A population-based study. Am J Respir Crit Care Med 1997; 156: 1413-1420.

38 de Torres JP, Campo A, Casanova C, Aguirre-Jaime A, Zulueta J. Gender and chronic obstructive pulmonary disease in high-risk smokers. Respiration 2006; 73: 306-310.

39 Avino P, De Lisio V, Grassi M, et al. Influence of air pollution on chronic obstructive respiratory diseases: comparison between city (Rome) and hillcountry environments and climates. Ann Chim 2004; 94: 629-635.

40 Ko FW, Woo J, Tam W, et al. Prevalence and risk factors of airflow obstruction in an elderly Chinese population. Eur Respir J 2008; 32: 1472-1478. 